\title{
HUBUNGAN PERAN DOSEN DENGAN MOTIVASI BELAJAR MAHASISWA
}

\author{
Muslimin Ali*
}

\begin{abstract}
ABSTRAK
Pembangunan nasional merupakan usaha peningkatan kualitas manusia dan masyarakat Indonesia yang dilakukan secara berkelanjutan, berlandaskan kemampuan nasional, dengan memanfaatkan kemajuan ilmu pengetahuan dan teknologi serta memperhatikan tantangan perkembangan global. Menurut data yang diperoleh dari Administrasi Akademik Akademi Perawatan Dharma Bhakti Subang, bahwa Nilai Indeks Prestasi (IPK) Akper Dharma Bhakti Subang tahun 2013 rata-rata IPK 2,92, tahun 2014 rata-rata IPK 2,74 dan tahun 2015 rata-rata IPK 2,06 dan nilai tersebut belum memenuhi nilai standar kelulusan yang ditetapkan Akper Dharma Bhakti Subang adalah 3,00. Tujuan penelitian ini bertujuan untuk mengetahui hubungan peran dosen dengan motivasi belajar mahasiswa Akper Dharma Bhakti Subang. Penelitian ini merupakan penelitian deskriptif analitik dengan pendekatan cross sectional. Pengambilan data dilakukan dengan teknik total sampling dengan jumlah sampel 85 mahasiswa Akper Dharma Bhakti Subang Tahun 2015. Hasil penelitian menunjukkan peran dosen Akper Dharma Bhakti Subang berada pada kategori sangat baik sebanyak 87,1\%. Motivasi belajar mahasiswa Akper Dharma Bhakti Subang sebanyak 63,5\% responden berada pada kategori tinggi. Ada hubungan bermakna antara peran dosen dan motivasi belajar mahasiswa Akper Dharma Bhakti Subang ( $p$ value 0,001).
\end{abstract}

Kata Kunci : Peran, Motivasi dan Belajar

\begin{abstract}
A national development efforts to improve the quality of human and people of Indonesia are carried out on an ongoing basis, based on national capacity, by utilizing the advancement of science and technology as well as attention to the challenges of global development. According to data obtained from the Nursing Academic Administration Subang, that Value Performance Index (CPI) nursing academy Dharma Bhakti Subang in 2013 the average GPA of 2.92, in 2014 the average GPA of 2.74 and an average 2015 GPA 2.06 and the value is not met the passing standard value assigned nursing academy Dharma Bhakti Subang is 3.00. The purpose of this study aims to determine the relationship of the role of the lecturer with student learning motivation Nursing Academy Dharma Bhakti Subang.

This research is descriptive analytic with cross sectional approach. Data were collected with a total sampling with a sample of 85 students of the Nursing Academy Dharma Bhakti Subang 2015. The results show the role of professor nursing academy Dharma Bhakti Subang are in the very good category as much as $87.1 \%$. Students' learning motivation nursing academy Dharma Bhakti Subang as much as $63.5 \%$ of respondents were in the high category. There is a significant relationship between the role of professor and student learning motivation Nursing Academy Dharma Bhakti Subang (p value 0.001).
\end{abstract}

Keywords: Fun, Motivation and Learning 


\section{PENDAHULUAN}

Tujuan pembangunan bangsa Indonesia berlandaskan pada tujuan nasional bangsa seperti yang tercantum dalam Pembukaan Undang-Undang Dasar 1945, yaitu untuk melindungi segenap bangsa Indonesia dan seluruh tumpah darah Indonesia dan memajukan kesejahteraan umum, mencerdaskan kehidupan bangsa dan ikut melaksanakan ketertiban dunia yang berdasarkan kemerdekaan, perdamaian abadi dan keadilan sosial. ${ }^{1}$ Dalam rangka mencapai tujuan pembangunan tersebut maka diperlukan sumber daya manusia yang tangguh, mandiri serta berkualitas. Hal ini sejalan dengan ketetapan Majelis Permusyawaratan Rakyat (MPR) Republik Indonesia Nomor : IV/MPR/1999, tentang Garis-garis Besar Haluan Negara (GBHN) adalah sebagai berikut : ${ }^{2}$ Pembangunan nasional merupakan usaha peningkatan kualitas manusia dan masyarakat Indonesia yang dilakukan secara berkelanjutan, berlandaskan kemampuan nasional, dengan memanfaatkan kemajuan ilmu pengetahuan dan teknologi serta memperhatikan tantangan perkembangan global. ${ }^{2}$

Perancangan gerakan pembangunan berwawasan kesehatan sebagai strategi nasional menuju Indonesia Sehat 2025", mendukung usaha meningkatkan mutu sumber daya manusia yang sehat, cerdas, dan produktif serta mampu memelihara dan meningkatkan kesehatan masyarakat, sebagai salah satu arah pembangunannya. Untuk mencapai hal tersebut, maka diperlukan adanya suatu upaya peningkatan sumber daya manusia untuk mendukung strategi tersebut, upaya yang dilakukan adalah antara lain peningkatan kualitas calon tenaga kesehatan yang nantinya akan sangat berperan dalam pembangunan berwawasan kesehatan sebagai strategi nasional menuju Indonesia Sehat 2025. Kualitas calon tenaga kesehatan yang handal tersebut juga melibatkan peran serta dari sektor swasta dalam pengadaan atau mendidik calon tenaga kesehatan yang berkualitas.

Menurut Oemar Hamalik motivasi dibentuk oleh inner component dan outer component adalah perubahan dan diri seorang, merasa tidak puas dan ketegangan psikologis kebutuhankebutuhan yang ingin dipuaskan. Sedangkan outer component adalah tujuan yang hendak dicapai seseorang yang menjadi arah perilaku/perbuatannya. ${ }^{3}$

Dalam hal ini peranan Akademi Keperawatan Dharma Bhakti Subang adalah sangat penting sebagai salah satu lembaga pendidikan tinggi di Kabupaten Subang yang tugasnya mempersiapkan tenaga kesehatan yang profesional, berdaya saing tinggi dan berkualitas. Akper Dharma Bhakti Subang adalah program D III Keperawatan yang visinya adalah terwujudnya program D III Keperawatan yang berkualitas dan mampu menghasilkan ahli madya keperawatan (perawat profesional pemula) yang memiliki sikap profesional terhadap perkembangan dunia kerja nasional dan internasional, beretika serta memiliki jiwa mandiri.

Penelitian tentang motivasi belajar, khususnya motivasi belajar mahasiswa masih sangat terbatas. Dari penelitian yang ada, didapatkan informasi bahwa motivasi belajar mahasiswa masih relatif rendah. Penelitian M. Sugiri di Akper Rumah Sakit Depkes Bandung dengan mengukur prestasi belajar mahasiswa didapatkan bahwa 32,4\% motivasi belajar mahasiswa Akper Rumah Sakit rendah. ${ }^{4}$ Penelitian yang dilakukan oleh Tuti Susilowati tentang faktorfaktor yang berhubungan dengan motivasi siswa masuk perguruan tinggi negeri di SMUN 5 Bandung. Penelitian ini menunjukkan adanya hubungan antara variabel internal (jenis kelamin), variabel eksternal (sikap guru, administrasi pendidikan, dukungan orang tua) dengan motivasi siswa masuk perguruan tinggi negeri. ${ }^{5}$

Akademi Perawatan Dharma Bhakti Subang telah memiliki empat angkatan yang terdiri dari program kelas reguler dengan latar belakang pendidikan dari SMU (sederajat) dan program kelas reguler khusus dengan latar belakang pendidikan SPK. Sekarang jumlah keseluruhan mahasiswa tersebut adalah sebanyak 85 orang. 
Berdasarkan data hasil studi pendahuluan yang dilakukan pada tanggal 2 Mei 2015 diperoleh dari pengelola, mahasiswa dan beberapa pihak lain yang terlihat dalam sistem pendidikannya, dapat diketahui bahwa secara umum motivasi belajar mahasiswa Akper Dharma Bhakti Subang masih rendah $72 \%$. Hal tersebut diperkuat dengan data sekunder berupa daftar hadir perkuliahan, daftar hadir bimbingan laboratorium, dan sebagainya. Berdasarkan daftar hadir perkuliahan yang dihitung pada setiap akhir perkuliahan diperoleh data bahwa mahasiswa yang jumlah kehadirannya kurang dari $75 \%$ jumlah perkuliahan berkisar antara 20-30\% atau 10 sampai 15 orang dari jumlah mahasiswa setiap kelas, hal ini akan dapat mempengaruhi standar nilai dan kelulusan yang ditetapkan oleh Akper Dharma Bhakti Subang.

Menurut data yang diperoleh dari Administrasi Akademik Akper Dharma Bhakti Subang, bahwa Nilai Indeks Prestasi (IPK) Akper Dharma Bhakti Subang tahun 2013 rata-rata IPK 2,92, tahun 2012 rata-rata IPK 2,74 dan tahun 2014 rata-rata IPK 2,06 dan nilai tersebut belum memenuhi nilai standar kelulusan yang ditetapkan Akper Dharma Bhakti Subang yaitu 3,00 .

Pihak pengelola dan dosen pengajar mengemukakan bahwa sebagian besar mahasiswa tidak memahami tujuan pembelajaran di Akper Dharma Bhakti Subang semangat mengikuti perkuliahan masih rendah, masih jarangnya kegiatan belajar secara kelompok atau bersama dilakukan para mahasiswa, dan dari segi kehadiran masih ada mahasiswa yang memperoleh kehadiran kurang dari 75\% dari jumlah pertemuan yaitu sekitar 10-15 b mahasiswa. Dari data administrasi keuangan diketahui bahwa sebagian besar mahasiswa atau sekitar 50 orang yang tidak menyelesaikan administrasi keuangan tepat waktu, akibatnya mereka tidak diperbolehkan mengikuti ujian tengah/akhir semester. Bahkan sering terjadi mahasiswa menyelesaikan administrasi keuangannya pada saat ujian atau praktek lapangan berlangsung setelah mendapat teguran/ peringatan baik melalui surat ataupun lisan. Dalam hal pelaksanaan praktek lapangan terdapat perbedaan semangat antara kelas reguler dan kelas reguler khusus.

Sedangkan sebagian besar mahasiswa atau sekitar 50 orang berpendapat bahwa administrasi dan manajemen pendidikan yang dilaksanakan di Akper Dharma Bhakti Subang dinilai masih kurang hal ini dirasakan mahasiswa yang merasa tidak adanya suatu peraturan yang ditegakkan dengan benar, misalnya sangat berharap mahasiswa yang tidak disiplin dan masih kurangnya pengaturan yang baik tentang jadwal perkuliahan. Jadwal perkuliahan pada sore hari dianggap tidak efektif oleh sebagian mahasiswa. Mengenai metode pembelajaran, mahasiswa beranggapan bahwa metode yang digunakan oleh para dosen sangat monoton dan tidak variatif, hal ini menyebabkan mahasiswa merasa jenuh. Para dosen tidak berupaya mengembangkan metode pembelajaran dan hanya terpaku pada metode pembelajaran di kelas dengan menggunakan saran OHP/laptop dan papan tulis. Para dosen dinilai tidak memberi kesempatan pada mahasiswa untuk kreatif dan mengembangkan potensi. Bahkan beberapa dosen dinilai tidak disiplin oleh mahasiswa, misalnya pemberitahuan terlebih dahulu. Mengenai hubungan staf dengan mahasiswa, sebagian besar mahasiswa merasa dekat dengan staf. Dari karakteristik mahasiswa Akper Dharma Bhakti Subang, diperoleh data bahwa usia mereka berkisar antara 18-45 tahun yang terbagi menjadi mahasiswa program reguler dan mahasiswa program reguler khusus. Mahasiswa program reguler khusus sebagian besar merupakan karyawan/sudah bekerja sedangkan kelas reguler sebagian besar belum bekerja. Mereka berasal dari wilayah, Kabupaten Subang, Kabupaten Karawang, Kabupaten Purwakarta dan Kabupaten Indramayu dan sekitarnya.

Tujuan penelitian ini untuk mengetahui peran dosen dengan motivasi belajar mahasiswa Akper Dharma Bhakti Subang . 


\section{METODE PENELITIAN}

Penelitian ini merupakan penelitian deskriptif analitik dengan pendekatan cross sectional. Dalam penelitian ini yang dilakukan adalah menganalisis faktor-faktor yang berhubungan dengan motivasi belajar mahasiswa Akper Dharma Bhakti Subang antara variabel bebas dengan variabel terikat. Populasi dalam penelitian ini adalah seluruh mahasiswa Akper Dharma Bhakti Subang. Teknik pengambilan sampel secara total sampling yaitu sebanyak 85 orang. Analisis yang digunakan untuk mengetahui hubungan antara variabel bebas (peran dosen), dan variabel terikat (motivasi belajar mahasiswa Akper Dharma Bhakti Subang) dilakukan dengan uji statistik uji chi square.

\section{HASIL PENELITIAN}

Peran Dosen

Tabel 1. Distribusi Frekuensi Peran Dosen

\begin{tabular}{llcc}
\hline \multicolumn{1}{c}{ Variabel } & Kategori & Frekuensi & $\%$ \\
\hline Peran Dosen & Sangat Baik & 74 & 87.1 \\
& Kurang Baik & 11 & 12.9 \\
\hline Total & & 85 & 100 \\
\hline
\end{tabular}

Dari hasil penelitian menunjukkan bahwa sebagian besar penilaian mahasiswa Akper Dharma Bhakti Subang terhadap Peran dosen berada pada kategori sangat baik sebesar $87,1 \%$.

\section{Motivasi Belajar Mahasiswa}

Tabel 2. Distribusi Frekuensi Motivasi Belajar Mahasiswa

\begin{tabular}{llcc}
\hline Variabel & \multicolumn{1}{c}{ Kategori } & Frekuensi & $\%$ \\
\hline Motivasi belajar Mahasiswa & Rendah & 31 & 36.5 \\
& Tinggi & 54 & 63.5 \\
\hline Total & & 85 & 100 \\
\hline
\end{tabular}

Dilihat dari tabel 2 bahwa dari hasil penelitian menunjukkan bahwa sebagian besar motivasi belajar mahasiswa Akper Dharma Bhakti Subang berada pada kategori tinggi yaitu sebesar $63,5 \%$.

\section{Hubungan Peran Dosen Dengan Motivasi Belajar Mahasiswa}

Tabel 3. Distribusi Frekuensi Hubungan Peran Dosen Dengan Motivasi Belajar

\begin{tabular}{|c|c|c|c|c|c|c|c|c|}
\hline \multirow{3}{*}{ Peran Dosen } & \multicolumn{4}{|c|}{ Motivasi Belajar } & \multirow{2}{*}{\multicolumn{2}{|c|}{ Total }} & \multirow{2}{*}{\multicolumn{2}{|c|}{ Keterangan }} \\
\hline & \multicolumn{2}{|c|}{ Tinggi } & \multicolumn{2}{|c|}{ Rendah } & & & & \\
\hline & $\mathrm{n}$ & $\%$ & $\mathrm{n}$ & $\%$ & $\mathrm{n}$ & $\%$ & $X^{2}$ & Nilai $\mathrm{p}$ \\
\hline Kurang Baik & 2 & 2,4 & 9 & 10,6 & 11 & 12,9 & & \\
\hline Sangat Baik & 52 & 61,2 & 22 & 25,9 & 74 & 87,1 & $11.214^{\mathrm{a}}$ & 0.001 \\
\hline Total & 54 & 63,5 & 31 & 36,5 & 85 & 100 & & \\
\hline
\end{tabular}

Hasil penelitian menunjukkan Peran dosen yang sangat baik menimbulkan motivasi belajar yang tinggi sebesar $61,2 \%$ dan $25,9 \%$ motivasi rendah serta Peran dosen yang kurang baik menimbulkan motivasi belajar tinggi sebesar 2,4\% dan 10,6\% motivasi rendah. 
Secara statistik hubungan antara Peran dosen dengan motivasi belajar menunjukan hubungan yang bermakna. $(\mathrm{P}<0,05)$.

\section{PEMBAHASAN}

\section{Peran Dosen}

Peran adalah keadaan mental dan syaraf dari kesiapan yang di atar melalui pengalaman yang memberikan pengaruh dinamik atau terarah terhadap respon individu pada semua obyek dan situasi yang berkaitan dengannya. ${ }^{6}$ Peran adalah sesuatu yang dapat di pelajari (pendidikan), dibentuk dan Peran akan mencerminkan kepribadian seseorang. ${ }^{6}$

Oleh karena itu Peran seorang dosen dalam memberikan motivasi bagi mahasiswa itu sangat dibutuhkan karena secara tidak langsung dorongan dari dosen membuat seseorang bias melakukan dengan ada harapan, dosen adalah orang yang patut ditiru dan diikuti, maka wajar jika mahasiswa selalu membutuhkan motivasi dari seorang dosen, baik secara langsung misalnya dengan memberikan dorongan belajar, bercerita tentang suatu keberhasilan seseorang, memberikan arah tujuan hidup yang bermakna, atau secara tidak langsung yaitu Peran dosen yang baik, berakhlak mulia, rajin dan aktif, itu dapat diikuti oleh para mahasiswa.

Proses Peran dapat terbentuk dari beberapa komponen antara lain $:^{6}$

1. Komponen Afektif, komponen ini berkaitan dengan perasaan dan emosi tentang sesuatu. Contoh kita bias saja tidak takut suntik atau takut.

2. Komponen Kognitif, peran mengandung pemikiran atau kepercayaan tentang sesuatu. Contoh kita kadang berfikir suntik itu sakit tapi kalau tidak maka tidak sehat-sehat.

3. Komponen Perilaku, Peran terbentuk dari tingkah laku seseorang dan perilakunya, sehingga kita biasa menolak dan menerima suntikan dari dokter untuk kesehatan.

\section{Motivasi Belajar mahasiswa}

Dilihat dari hasil penelitian menunjukan bahwa sebagian besar motivasi belajar mahasiswa Akper Dharma Bhakti Subang dengan kategori tinggi sebesar 63,5\% dan 36,5\% menunjukan bahwa motivasi belajar mahasiswa Akper Dharma Bhakti Subang dengan kategori rendah. Faktor-faktor yang berhubungan dengan Motivasi Belajar Mahasiswa adalah umur, pendidikan terakhir, sumber dana, program pendidikan, dan administrasi pendidikan ${ }^{6}$.

\section{Hubungan Peran Dosen dengan Motivasi Belajar Mahasiswa}

Pada uraian hasil penelitian tersebut di atas di dapat data bahwa Peran dosen sangat baik $87,1 \%$ menimbulkan motivasi belajar tinggi sebesar $61,2 \%$ dan $25,9 \%$ motivasi rendah serta Peran dosen kurang baik menimbulkan motivasi belajar tinggi sebesar 2,4\% dan 10,6\% motivasi rendah. Secara statistik hubungan antara Peran dosen dengan motivasi belajar menunjukan hubungan yang bermakna. $(\mathrm{P}<0,05)$.

Melihat data tersebut bahwa hal ini dapat di katakana bahwa peran dosen dan motivasi belajar mahasiswa sangat berhubungan yang signifikan, artinya Peran dosen dapat ikut serta berperan dalam rangka memberikan motivasi dalam keberhasilan mahasiswa dalam belajar, oleh karena itu Peran dosen yang baik dan inovatif dalam dunia akademik itu sangat baik untuk perkembangan anak didiknya.

Jika motivasi dan peran dosen dapat diterapkan dalam waktu pengajaran, maka keberhasilan seorang dosen dalam menghantarkan anak didiknya akan mudah didapat, secara langsung peran itu tertransfer ke otak mahasiswa, sehingga dengan transformasi peran, tingkah laku dari dosen maka dengan sendirinya belajar mahasiswa itu termotivasi.

Sedangkan Maslow, menjelaskan bahwa manusia yang dikuasai oleh kebutuhan yang tidak terpuaskan akan termotivasi untuk melakukan kegiatan guna memuaskan kebutuhan 
tersebut. Teori tersebut menggambarkan hubungan hierarkis dari berbagai kebutuhan, di mana kebutuhan pertama merupakan dasar untuk munculnya kebutuhan lain. Jika kebutuhan pertama telah terpuaskan, maka manusia mulai dari keinginan untuk memenuhi kebutuhan berikutnya. Namun apabila suatu kebutuhan telah terpuaskan maka tidak berarti kebutuhan tersebut tidak akan muncul lagi selamanya, dengan kata lain bahwa kepuasan terhadap suatu kebutuhan hanya bersifat sementara. ${ }^{7}$

Mc. Donald, memandang motivasi sebagai suatu proses dalam diri individu, di mana pengetahuan tentang proses tersebut dapat membantu kita untuk menjelaskan tentang tingkah laku seseorang yang kita amati. Mc. Donald menentukan karakter proses (motivasi) tersebut dengan beberapa tingkah laku yang dapat diamati, yaitu (1) motivasi diawali dengan adanya perubahan energi dalam pribadi/diri seseorang berupa perubahan-perubahan neurologis dalam organisme manusia, misalnya terjadi perubahan dalam sistem pencernaan maka timbul motif lapar. (2) Motivasi ditandai dengan timbulnya suatu perasaan affective arousal. Yang awalnya berupa ketegangan psikologis, lalu merupakan suasana emosi, menimbulkan perilaku yang bermotif. Misalnya seseorang terlibat dalam suatu diskusi, karena dia merasa tertarik pada masalah yang dibicarakan, maka suaranya akan lantang dan kata-katanya akan keluar dengan lancar dan cepat, (3) motivasi ditandai dengan reaksi-reaksi untuk mencapai tujuan pribadi dengan mengadakan respon-respon yang tertuju ke arah tujuan mengurangi ketegangan yang disebabkan oleh perubahan energi dalam dirinya, misalnya seseorang ingin mendapat hadiah maka ia akan belajar, mengikuti ceramah, bertanya, membaca buku dan mengikuti les. ${ }^{8}$

Oleh karena itu hemat peneliti Peran dosen yang baik terus perlu di kembangkan baik secara akademik maupun secara individu agar kegiatan semacan itu dapat memberikan motivasi belajar dan keberhasilan bagi siapa saja yang dapat melihat dan menirunya.

\section{SIMPULAN}

Berdasarkan hasil penelitian dan pembahasan yang telah diuraikan diatas, maka dapat diambil kesimpulan sebagai berikut :

1. Peran dosen Akper Dharma Bhakti Subang menunjukkan kategori sangat baik $(87,1 \%)$.

2. Motivasi belajar mahasiswa Akper Dharma Bhakti Subang menunjukkan bahwa motivasi belajar kategori tinggi $(63,5 \%)$.

3. Peran dosen dan motivasi belajar mahasiswa menunjukkan hubungan yang bermakna dengan nilai Pvalue $(\mathrm{P}<0,05)$.

\section{SARAN}

1. Bagi Akper Dharma Bhakti Subang

Pengelolaan program studi Akper Dharma Bhakti Subang agar lebih meningkatkan kembali dalam memberikan motivasi dan bimbingan belajar pada mahasiswa agar prestasinya lebih baik.

2. Bagi Dosen

Bagi para dosen Akper Dharma Bhakti Subang agar datang tepat pada waktunya dan apabila berhalangan mengajar hendaklah memberikan informasi sebelumnya ke program studi.

3. Bagi Mahasiswa Akper Dharma Bhakti Subang

Mahasiswa diharapkan agar belajar yang rajin, datang tepat waktu, mengerjakan tugas dan terus berusaha bermotivasi dalam belajar.

4. Bagi Perawat

Hasil penelitian ini agar dapat dijadikan masukan bagi perawat agar kelak jika ingin menjadi seorang dosen di perguruan tinggi agar mempunyai Peran yang baik sehingga menjadi inspirator dan motivator bagi mahasiswa. 
5. Bagi Istitusi Pendidikan

Hasil penelitian ini sebagai bahan bagi Akper Dharma Bhakti Subang untuk menyampaikan kepada semua dosen agar mempunyai Peran dan perilaku yang dapat memberikan motivasi bagi mahasiswa.

6. Bagi Peneliti Lain

Hasil penelitian ini dapat dijadikan dasar dan bahan untuk penelitian selanjutnya pada bidang yang sama, sehingga akan menghasilkan penelitian yang lebih baik lagi.

\section{DAFTAR PUSTAKA}

1. Depkes RI. Program Indonesia sehat. Jakarta : Depkes; 2004.

2. Depdikbud RI. Tap MPR RI No. IV/MPR/1999. Jakarta : Depdikbud RI; 2005

3. Hawalik, Oemar. Kurikulum dan pembelajaran. Jakarta: Bumi Aksara; 2006

4. M.Sugiri. Faktor-faktor yang berhubungan dengan motivasi siswa masuk perguruan tinggi Negeri di SMAN 1 Subang. Subang: IKIP Bandung Program Ilmu Pendidikan; 2005.

5. Susilowati, Tuti, Faktor-faktor yang berhubungan dengan motivasi siswa masuk Perguruan Tinggi Negeri di SMUN 5 Bandung: IKIP Bandung Program Pendidikan; 2005.

6. Raymond J. Wlodkowski, Judith H. Jaynes. Motivasi belajar. Jakarta: Cerdas Pustaka; 2004.

7. Moslow H., Abraham. Motivation and personal. New York: Paper and Row Publisher; 2005.

8. Ary, Donald. Introduction In Research In Education. Sydney: Hott Rinehart and Winsto; 2005 